\title{
Is forest related decision-making in European treeline areas socially innovative? A Q-methodology enquiry into the perspectives of international experts
}

\author{
Maria Nijnik $^{\mathrm{a}, *}$, Anatoliy Nijnik ${ }^{\mathrm{b}}$, Simo Sarkki $^{\mathrm{c}}$, Jose Muñoz-Rojas $^{\mathrm{d}}$, David Miller ${ }^{\mathrm{e}}$, Serhiy Kopiy ${ }^{\mathrm{f}}$ \\ a Social, Economic and Geographical Sciences Group, The James Hutton Institute, Craigiebuckler, Aberdeen AB15 8QH, United Kingdom \\ ${ }^{\mathrm{b}}$ Environmental Network Ltd, Aboyne, United Kingdom \\ ${ }^{c}$ Thule Institute, University of Oulu, P.O. Box 7300, 90014 Oulu, Finland \\ d Landscape Dynamics and Social Processes, Instituto de Ciências Agrárias e Ambientais Mediterrânicas, Universidade de Évora Apartado, 94, 7006-554 Évora, Portugal \\ e The James Hutton Institute, Craigiebuckler, Aberdeen AB15 8QH, United Kingdom \\ ${ }^{\mathrm{f}}$ Ukrainian National Forestry University, Henerala Chuprynky St, 103, L'viv 79000, Ukraine
}

\begin{abstract}
A B S T R A C T
Treeline areas provide a range of ecosystem services, but there are diverging views as to how and for whose benefit, these ecosystem services are managed. Applying a Q-method, we explore experts' attitudes towards forest related decision-making and governance in treeline areas to reveal the attitudinal divergences that exist and analyse patterns of shared assumptions forming attitude-related communities. Experiences, trends, opportunities and challenges in European treeline area decision-making are considered. Our results reveal four attitude-related communities, representing four distinctive types of expert attitudes. Findings demonstrate a number of similarities in attitudes among experts indicating, for example, that treeline area decision-making is hardly socially innovative as it tends to happen in a top-down manner. However, some do and others don't see tree-line governance beneficial from an ecological perspective. The attitudinal heterogeneity identified offers insights into treeline decision-making and could, therefore, be useful to public decision-makers in addressing the opinions of each attitudinal group on a case-by-case basis. The general conclusions are that forest related decision-making in treeline areas requires social innovation and a high level of stakeholder competence and capacity-building; and that an improved knowledge of experts' attitudes, together with an emphasis on increased participation in decision-making, could be of help to policy and practice communities in triggering innovative changes locally.
\end{abstract}

\section{Introduction}

Treeline areas are rural landscapes where altitude/latitude, relief, and climate create special conditions influencing land use and related economies, societies and cultures (SENSFOR, 2013). These areas provide a variety of ecosystem services of value to many different stakeholders, including those related to forestry, agriculture and wider rural development (European Commission, 2010; Gret-Regamey et al., 2013). Key elements of policy-driven changes in such, primarily marginalised, areas include land use changes, development of infrastructure, renewable energy, recreation, landscape conservation etc. (Muñoz-Rojas et al., 2015). The changes create challenges and require effective decisions to be made at a local level, as well as participatory governance and ecosystem based management practices to be implemented (Sarkki et al., 2015).
Common characteristics that are particularly associated with treeline areas include: depopulation, comparatively low living standards, soil and water erosion and increasing impacts of natural disturbances (Brang et al., 2006). Furthermore, land abandonment (EEA, 2010) which is often followed by secondary succession of wood vegetation, is observed in the treeline areas of a number of EU countries (Lasanta et al., 2005; Gellrich et al., 2007; González-Puente et al., 2014), while intensification of land use practices is noticed in some others (EEA, 2010). Current changes in the agriculture sector challenge the conservation of cultural landscapes, leading in some instances to the loss of ethnically-related cultural traditions (Bürgi et al., 2004). The expansion of certain novel local businesses and activities can be seen as a means of economic advance. However, some of these developments create additional challenges (González-Puente et al., 2014), including institutional, specifically related to the lack of transparency (Heikkinen et al.,

\footnotetext{
* Corresponding author.

E-mail addresses: maria.nijnik@hutton.ac.uk (M. Nijnik), anijnik@yahoo.com (A. Nijnik), simo.sarkki@oulu.fi (S. Sarkki),jmrojas@uevora.pt (J. Muñoz-Rojas), david.miller@hutton.ac.uk (D. Miller).
} 
2010) and problems in balancing top-down and bottom-up governance mechanisms, difficulties in knowledge exchange (Huber et al., 2013), and lack of stakeholder influence in the co-construction of knowledge to inform policies, leading to insufficient local end-user involvement in the decision-making (Sandström, 2009).

Treeline areas should be governed so as to enable a balanced, fair, and sustainable use of the multiple ecosystem services they provide (Kaljonen et al., 2008). Various governance instruments, including administrative regulations, development plans and education, advisory and extension services seek to manage multi-functional challenges at a local level. Market-based instruments have lately been gaining importance, including various kinds of certification, compensation mechanisms and incentives.

Also, social innovations re-emerged as a concept and practice (Cajaiba-Santana, 2014; Bock, 2015; Neumeier, 2016) to advance the transition towards sustainable development (European Commission, 2016) and to promote smart and inclusive growth (SIMRA, 2016). The innovation theories have moved towards recognising the critical role of social capital and stakeholder engagement with trust among policy actors considered as increasingly important (Fukuyama, 1995). The idea of regional innovation systems (Asheim and Isaksen, 2002) the success of which is contingent on social capital has been promoted. Close connections between regional innovation systems and the innovative milieu have been developed, with Camagni (1995) recognising the significance of social relationships and institutional factors for sustainable development, and again providing connections to social capital (Coleman, 1988; Putnam, 2000; Lehtonen, 2004). It is believed that social innovations and connected new governance mechanisms strengthen actors' ability to respond to societal challenges (Lehtonen, 2004) and foster the delivery of ecosystem services.

However, implementing multi-functionality on the ground is difficult because of historic traditions of managing treeline ecosystems for single or complementary services (Kaljonen et al., 2008). Satisfying contemporary objectives related to multi-functionality is also problematic since the combination of diverse ecosystems and their services differ among locations (Nijnik and Miller, 2014). Moreover, multiple and diverse stakeholders have different interests, values, and beliefs; while their attitudes and perceptions of the quality of governance and decision-making, and their priorities with respect to individual ecosystems and their services, are often even more variable (Sarkki et al., 2015). The high levels of difficulty that are inherent in implementing effective governance frameworks in multi-functional rural areas has rendered such a challenge as "wicked" (i.e. a partially intractable problem) (Duckett et al., 2016). This is clearly the case in treeline areas where the heterogeneity of conditions is strong due to drastic changes in altitude and climate. Furthermore, treeline areas are often characterized by social and economic marginalization processes, as well as by loss of biodiversity and degradation of landscape quality (SENSFOR, 2013). Although these problems are generically associated in the wider context of European uplands, in treeline areas they are unequivocal.

Until recently, top-down governance has been conventional in rural areas. However, these regimes are being questioned because of their inability to deliver social and democratic objectives (Ostrom, 2011; Jessop and Sum, 2006; Hodge, 2013). Bottom-up (Adger, 2003) and multi-level (Andonova and Mitchell, 2010) frameworks have been presented as alternatives, leading to a paradigm shift towards localism, subsidiarity, and local empowerment (Muñoz-Rojas et al., 2015). However, in the course of any institutional transition, a lack of horizontal cooperation and gaps in vertical coordination are predictable (Nijnik and Oskam, 2004; Bizikova et al., 2012). At times, these lead to conflicts between local people, policy, planning and governance actors, and land managers (Eckerberg and Sandstrom, 2013).

Also, whereas the policy intent in the EU context is to downscale the level of decision-making towards the end-user, planning and policy frameworks and instruments often remain numerous and complex for the downscaling to become effective (Muñoz-Rojas et al., 2015). Thus, there is a need to explore the feasibility of rural area governance to deliver on the objectives related to balanced, fair, and ecologically sustainable land use systems. Multiple drivers heavily impacting treeline areas act across a range of scales. Therefore, treeline areas are indicative of trends in global changes and can provide science with a valuable opportunity to examine the challenges that forest governance currently faces (Heikkinen et al., 2012). Furthermore, treeline areas can serve as a living laboratory for testing potentially useful governance models and approaches to tackle "wicked" problems. For a critical definition of such problems, see Duckett et al. (2016).

However, the literature addressing governance and decision-making in treeline areas is limited (Sarkki et al., 2015). There is a knowledge gap in understanding how socially innovative the decision-making is in treeline areas, specifically how well current governance practices can cope with and respond to socio-environmental changes, and to new demands posted at local, regional, and global levels. Do stakeholders perceive that treeline environmental decision-making can be considered as being "good governance" and do they see potentials to develop socially innovative decision-making? We, therefore, consulted international experts to fill this knowledge gap and to assess the degree of their alignment regarding attitudes towards, and perceptions of, various aspects of governance in European treeline areas.

In this paper, we identify and examine experts' attitudes and perceptions concerning forest-related governance, as well as the role and place of science in bridging knowledge gaps in understanding treeline governance and stakeholder engagement in order to reveal the heterogeneity of expert attitudes towards forest related decision-making and analyse patterns of shared assumptions forming attitude-related communities (in parallel to a certain extent to what Haas, 1992 names as epistemic communities). This was done by using Q-methodological research tools which enable researchers to identify commonalities and divergences across attitude-related communities. Such an assessment is deemed to be useful to assess the state and quality of forest governance, as viewed through the eyes of international experts and to advance knowledge which could be used to design improved governance systems, which are more socially innovative.

An expert is a person with extensive knowledge or ability based on research, experience, or occupation in a particular area of study or practice (Ericsson et al., 2006). It would be indeed a mistake to consider that experts hold a uniform and particular view. We acknowledge that while they may hold divergent views (Nijnik et al., 2014) commonalities can be found. Nijnik et al. (2010) and Sarkki et al. (2014) show that there may be divergences and synergies in experts' attitudes and perceptions. For example, divergences have been observed between traditional and culturally important land uses and conservationists (Heikkinen et al., 2012). Thus, various groups of experts may form attitude-related communities (sensu epistemic communities, as per Haas, 1992) that share certain assumptions (e.g. on how governance functions and how it can be improved). Identifying and examining these perspectives is important, because the creation of good practices necessitates an improved understanding of the diversity of attitudes; and examining expert attitudes can contribute to an exploration of feasible options and identify pathways towards more innovative, participatory and bottom-up governance.

We believe that empirical material documenting expert attitudes towards treeline governance has various benefits. Firstly, the participating experts have years of experience in various aspects of policy, planning and governance in European treeline areas, and can therefore provide synthesized and more realistic and thus applicable knowledge. Secondly, this group of stakeholders can reflect on treeline areas largely based on knowledge that is co-constructed with the relevant end-users, thus making it easier to understand and implement. Thirdly, acknowledging experts' different ways of reasoning is important for producing more societally relevant knowledge and gaining access to understanding of the 'real world' problems and their potential solutions (Sarkki et al., 2013). Lastly, expert knowledge can contribute 
information useful to fulfilling the existing need to improve policy integration and management approaches in order to deliver the competing ecosystem services demanded by society that are potentially provided by treeline areas.

The paper starts with an explanation of the method applied. In the results section, the quantitative analyses are interpreted to construct typologies of experts' perspectives. We briefly explain the attitudinal heterogeneity in terms of contextual and personal factors. After presenting the main findings, we discuss the opportunities and challenges of triggering multi-functional changes locally and their implications for improved planning and governance of treeline areas. The conclusion highlights key findings and relevance of the methods used.

\section{Methodological considerations}

\subsection{The Qmethod explained}

To reveal and examine commonalities and divergences in experts' attitudes and perceptions on how treeline governance can be realized we applied the Q-method which originally was developed in psychology (Stephenson, 1963). The Q-method is a participatory, systematic and rigorous scientific tool designed to reveal and examine subjective attitudes and perspectives; to provide insights into attitudinal diversity and human preferences; to identify criteria of the issue in question that are important to people; and to explain major factors influencing the heterogeneity of stakeholder beliefs (Watts and Stenner, 2012). This method (Schmolck, 2012) combines qualitative and quantitative tools (Brown, 1999; van Exel and De Graaf, 2005) and incorporates elements of behavioural studies into action research (Nijnik et al., 2014; Miller et al., 2009). Unlike standard survey analysis, the Q-method enables researchers to discover similarities and differences across the attitudes and perceptions of individuals, yet not across their socio-economic or other traits. The method (Brown, 2004; Davies and Hodge, 2012) has been used to structure the so-called "wicked problems" (Cuppen, 2009; Duckett et al., 2016), including those found in rural areas (Previte et al., 2007; Hermans et al., 2012; Nijnik et al., 2016). Comprehensive information about it and its comparison with standard R-analysis is available in Addams and Proops (2000), Brown (2004) and van Exel and De Graaf (2005).

In order to identify individual attitudes on a specific issue, respondents are asked to sort a set of statements representing positions on different sub-elements of the issue in question. These statements should, as closely as possible, represent the entire communication on the issue, i.e. the concourse (Stevenson, 2015). The sorting is done on a specified scale (usually using a normal distribution chart) and results in what is called a Q-sort, i.e. the formal model of each respondent's attitudes. Then, each Q-sort is correlated with every other Q-sort, and their inter-correlation matrix is factor-analyzed. This potentially enables the identification of attitudinal clusters (Brown, 1999); and, because these clusters are associated with respondents, the technique enables linking the identified clusters (typologies) of attitudes to the individual background characteristics of respondents. The resulting Qsorts represent the attitudes people have, allowing us to suggest some underlying (societal) values that seem to be associated with certain discourses unveiled (McKeown and Thomas, 2013). It is important to indicate that this achievement would never, under the terms hereby explored, constitute by itself the ultimate explanation of attitudinal heterogeneity or of the societal values that underpins it. Nevertheless, it does provide a hint to unveiling attitudinal heterogeneity, a goal that might be improved under further work, where respondents might be asked about generalised trust questions.

The Q-method allows for a rather simple data set (Robbins, 2005) because most of the data in this type of analysis derives from how much information is implicit in each participant's Q-sort (Barry and Proops, 1999). By applying the Q-method we can examine areas of consensus and disagreement among people, a form of knowledge that we argue is

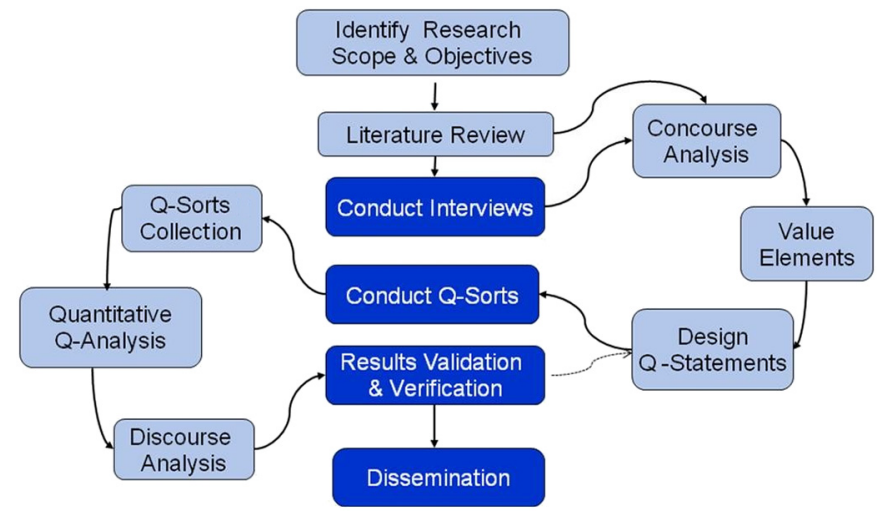

Fig. 1. The sequencing of steps in a Q-method study.

useful in specifying, selecting, and evaluating policy and decisionmaking. This in itself is an important target for policy analysis and evaluation, and is documented to have been so at least for the past half a century, as indicated by Lasswell (1971).

\subsection{Applying the Q-method to analyse experts' attitudes to governance in treeline areas}

The process involved the following steps (Fig. 1). First, statements were derived through a concourse analysis (the Latin 'concursus' means 'running together') when knowledge can be derived from interviews or written narratives and can be comprised of discourses and media (Davies et al., 2005). Statements can be naturalistic, ready-made or hybrid samples and they can be structured or unstructured by design (Brown, 2004). Commonly, statements emerge from interviews and communication with stakeholders. However, they can alternatively be derived from secondary sources (McKeown and Thomas, 2013; Stevenson, 2015). Therefore, to match research objectives and be time/ resource efficient we decided to draw on existing material. The most important aspect of compiling statements is to ensure that they reflect public debates. Therefore, a rigorous and extensive process of data collection was conducted. For this purpose we used available research results (e.g. surveys in the form of reports, blogs, etc.) and reviews of literature on environmental policy, planning and governance, decisionmaking, and science-society relationships, particularly those associated with forest policy and management issues in marginalised mountain areas (Sarkki, 2011; Sarkki et al., 2013; Sarkki and Heikkinen, 2010; Heikkinen et al., 2010; Heikkinen et al., 2012; Nijnik et al., 2010).

To assess whether and how treeline area governance can become more inclusive we used insights from the White Paper on European Governance (EC, 2001) which identifies five principles of 'good governance': participation, openness, accountability, effectiveness and coherence. Additionally, we added a theme of adaptive co-management and social innovation (Berkes, 2009; SIMRA, 2016) to be considered as part of good governance. We then consulted relevant experts within the SENSFOR (Enhancing the Resilience Capacity of Sensitive Mountain Forest Ecosystem under Environmental Change) COST Action and derived Q-statements in relation to the following themes linked to the subelements of treeline area planning and governance which are of importance to our research. Below we also identify which of the statements (presented in Appendix) addresses each of the following themes:

- Participation is important for substantive, instrumental and normative goals of governance (Stirling, 2006). We assessed participation as linked to whether stakeholders have opportunities to participate in decision-making processes, and whether they believe that their views are taken into account. We investigated whether respondents felt that participation was socially innovative, genuine or merely rhetorical/tokenistic (Arnstein, 1969; Rauschmayer et al., 
2009). We assessed participation using the statements of $1 ; 3 ; 4 ; 5$; $8 ; 9$ and 22.

- Coherence and accountability are especially relevant in a multi-level governance context where various governance levels are vertically (across scales) and horizontally (across sectors) connected (Newig and Fritsch, 2009). We measured coherence by assessing whether the various decision nodes in multi-level contexts are in contradiction with each other, or whether they provide a coherent set of governance instruments. Accountability refers to responsibilities of public decision makers, planners and other governance actors to take stakeholders' views into account (Bäckstrand, 2003). We assessed coherence and accountability using the statements of $10 ; 13$; $17 ; 24$ and 25.

- Openness links especially to transparency of decision-making (Wilson, 2009). Trust between local stakeholders and other governance actors, as a characteristic of social innovation, is often a result of openness and transparency, while rumors and public criticism against decision-making is a sign of problems regarding openness (Heikkinen et al., 2012). We assessed openness using the statements of $2 ; 19 ; 20 ; 21$ and 23 .

- Effectiveness relates especially to outcomes resulting from governance arrangements (Newig and Fritsch, 2009). Regulatory instruments are considered to be conventional in treeline areas (SENSFOR, 2013). The emergence of market based instruments, as parallel governance tools, implies that regulatory mechanisms have not been effective, and that additional mechanisms, e.g. based on social innovation, are therefore needed (Muñoz-Rojas et al., 2015). The effectiveness of policy and planning instruments is case and context specific, and to assess it we examined perceptions of environmental outcomes and market-based instruments applicable to treeline areas by using the statements of 14; 18; 26 and 27.

- Adaptive co-management implies learning from past experiences, being socially innovative and flexible to changes, using science to reflect on governance and co-constructing knowledge with stakeholders (Berkes, 2009). Social innovations manifest themselves in new social relationships (institutional environments and arrangements) and related actors' interactions and collaborations (e.g. new practices, processes and networks), and new fields of activity (e.g. social entrepreneurship and social enterprises). Capacity and trust building, knowledge sharing and learning-by-doing, as well as strengthening of science-society-policy relationships and boosting social innovation is considered essential for 'good' governance (Funtowicz and Ravetz, 1993; Nijnik and Oskam, 2004) and enhanced forest policy and planning. We assessed these issues with the statements of $6 ; 7 ; 11 ; 12 ; 15$ and 16.

The statements, therefore, reflected on 'stakeholders' needs' in European treeline areas as these are linked to ecosystems and their services, environmental/forest policy and planning, governance and its procedures, including the roles of science and stakeholder involvement in the decision-making processes. The final list consisted of 29 statements, and there were correspondingly 29 boxes in the normal distribution chart. The sorting grid looked like (the first figure stands for the value of the column and the second, in brackets, shows the column size): -5 (1); - 4 (2); - 3 (2); - 2 (3); - 1 (4); 0 (5); + 1 (4); + 2 (3); $+3(2) ;+4(2) ;+5(1)$.

Statements and the procedure design were pre-tested with our colleagues and improved in line with the feedback received. The final statements were presented to professionals from 20 European countries having expertise in various aspects of planning, decision-making and governance in treeline areas. It was undertaken during the COST Action ES1203 meeting of September 2013 in Jaca, Spain. In the context of Qmethodology (as an inversion of $\mathrm{R}$ methodology) the statements constitute the sample and each participant is a variable (Stevenson, 2015). As explained by Watts and Stenner (2012), randomly selecting participants would therefore be as illogical as randomly selecting variables in a traditional survey.

The SENSFOR network consisted of over one hundred experts on treeline areas representing mostly mountainous, peripheral and marginalised regions of Europe with relatively low human impact. Following consultation to all experts and researchers participating in the Jaca meeting we received responses from 30 experts, who were diverse in their socio-cultural, economic, political-historic and educational backgrounds and represented different geographical regions and types of European treeline areas. Examples of the bio-geographical heterogeneity represented by those responding include Mediterranean and Central European Alpine Mountain chains (Alps and Pyrenees mainly, but also older Iberian massifs), the Carpathians and Scottish highlands and others, from Scandinavia. Among these contexts, treeline areas may vary enormously in their geographical and bio-physical conditions, turning the sample of respondents wide enough. This variability is even greater among the socio-cultural characteristics within each of these contexts. The participation of respondents during a meeting in Jaca, under the umbrella of a clearly oriented research network, made us confident that participants would be both experts and well aware of the issues at stake in this discussion. Furthermore, them being volunteers helped us secure their interest to participate and contribute to the discussion.

The sorting instructions were explained and made available at the beginning of the session. It was a desk-based exercise, with the statements printed on cards, and a preliminary round of pile sorting conducted first. Respondents were asked to sort the statements on the scale ranging from +5 through -5 , judging on the statements in relation to each other, with " +5 " indicating full agreement, "-5" indicating full disagreement, and "0" showing a neutral attitude (which could also mean 'ambivalent', or 'don't know', depending on the respondent). As it is commonly done in the Q-sorting process, we gave each of the respondents an opportunity to rearrange the individual matrix (Q-sort) until it best reflected the subjective position.

Additionally, to deepen our insights into environmental policy discourses (i.e. to test whether/how the social-economic characteristics of respondents may influence the discourses), questions were asked about the socio-economic background of respondents, i.e. their gender; age; work experience; education; income level; partnership status and number of children.

After our respondents had positioned the statements across the charts, the output data (i.e. the 30 completed Q-sorts) were assessed using the sequential application of correlation and Principle Component Analysis (PCA). As explained in the previous section, we used correlation analysis to compare the attitudes among respondents. Regular PCA was used to categorize correlated expert views into different 'factors' by creating new uncorrelated choice variables that captured the common essence of the correlated individual Q-sorts (Nijnik et al., 2014). These so-called 'factors' permit capturing the variety of individual attitudes and structure them in such a way that different 'common discourses' emerge (Schmolck, 2012; Stevenson, 2015); thereby allowing a comparison of key differences and similarities between the identified ' $f a c$ tors' (i.e. attitudinal groups). The final steps included interpretation of the social discourses unveiled through the quantitative analysis; contrasting the value outputs with the socio-economic background of respondents; and verifying and communicating the results with/to respondents.

\section{Results}

\subsection{Heterogeneity of expert attitudes}

The modelling outputs (Table 1 ) received through factor extraction (PCA), Varimax rotation, and interpretation demonstrated that four factors (with factor correlations range from -0.03 to 0.28 ) provide the best representation of distinctive types of existing attitudes, or discourses. These factors have an Eigenvalue (i.e. the sum of its squared 
Table 1

Factor matrix with an $\mathrm{X}$ indicating a defining sort.

\begin{tabular}{|c|c|c|c|c|}
\hline QSORT & 1 & 2 & 3 & 4 \\
\hline 1 & $0.5982 X$ & 0.3748 & 0.1915 & $0.4128 \mathrm{X}$ \\
\hline 2 & -0.1022 & 0.2891 & $0.5161 X$ & 0.0167 \\
\hline 3 & 0.0052 & $0.5928 \mathrm{X}$ & -0.0785 & -0.0781 \\
\hline 4 & -0.0756 & 0.0402 & $0.6632 \mathrm{X}$ & -0.3130 \\
\hline 5 & $0.5465 \mathrm{X}$ & 0.4488 & -0.0980 & 0.3454 \\
\hline 6 & $0.7933 X$ & 0.1194 & 0.0306 & 0.0532 \\
\hline 7 & 0.0168 & -0.0975 & $0.7572 X$ & -0.0398 \\
\hline 8 & $0.4618 \mathrm{X}$ & 0.0342 & 0.0320 & $0.4567 \mathrm{X}$ \\
\hline 9 & 0.0582 & 0.0046 & -0.0480 & $0.6672 X$ \\
\hline 10 & $0.5268 \mathrm{X}$ & -0.0184 & $0.5158 \mathrm{X}$ & 0.3431 \\
\hline 11 & 0.1794 & $0.5367 X$ & -0.1337 & $-0.4944 \mathrm{X}$ \\
\hline 12 & $0.5634 \mathrm{X}$ & 0.3451 & 0.1248 & 0.2629 \\
\hline 13 & $0.6032 X$ & 0.0924 & -0.0133 & -0.1262 \\
\hline 14 & $0.6793 X$ & 0.1236 & -0.0702 & -0.0662 \\
\hline 15 & 0.2197 & $0.7551 X$ & 0.2381 & -0.0974 \\
\hline 16 & 0.1295 & 0.2247 & 0.0671 & 0.3288 \\
\hline 17 & -0.0709 & 0.4203 & -0.3736 & $0.4432 X$ \\
\hline 18 & -0.0582 & -0.0562 & $0.5845 \mathrm{X}$ & 0.2181 \\
\hline 19 & -0.1408 & $0.6438 \mathrm{X}$ & -0.0817 & 0.1450 \\
\hline 20 & -0.4875 & 0.3174 & 0.3645 & 0.1692 \\
\hline 21 & 0.4620 & $0.4688 \mathrm{X}$ & 0.0627 & 0.0107 \\
\hline 22 & 0.4085 & -0.2023 & $0.4055 \mathrm{X}$ & 0.0606 \\
\hline 23 & $-0.5990 \mathrm{X}$ & 0.0144 & 0.3856 & 0.3689 \\
\hline 24 & -0.0397 & $0.5615 X$ & 0.0709 & 0.1151 \\
\hline 25 & 0.3166 & $0.5188 \mathrm{X}$ & 0.2074 & 0.2130 \\
\hline 26 & 0.1821 & $0.5947 X$ & -0.0090 & -0.1725 \\
\hline 27 & $-0.7154 X$ & 0.3404 & -0.1927 & -0.0090 \\
\hline 28 & 0.1813 & 0.0977 & $0.3964 X$ & -0.1391 \\
\hline 29 & 0.4302 & 0.4302 & -0.0175 & 0.2917 \\
\hline 30 & 0.1085 & 0.1205 & 0.0907 & $-0.6069 \mathrm{X}$ \\
\hline$\%$ expl. var. & 16 & 13 & 10 & 9 \\
\hline
\end{tabular}

factor loadings) of $>1.00$, and each factor has more than two significant factor loadings (i.e. at least two respondents are highly correlated with that factor and no other). The rows in Table 1 depict the respondents with their views (i.e. individual Q-sorts). The numbers represent the factor loadings, which are correlation coefficients that indicate the extent to which each of the 30 individual Q-sorts is similar/ dissimilar to each of the four composite factor arrays. The rows in Table 1 depict the respondents with their views (i.e. individual Q-sorts).

A positive factor loading indicates that the person shares subjectivity of the attitudinal group, whilst negative loadings are a sign of rejection of the attitudinal group's perspective. X-flagging indicates the most decisive and defining individual Q-sorts for each factor. Numbers at the bottom of the table show the variance (\%) in the total dataset of individual Q-sorts, as explained by the factors. The four factors cumulatively captured $48 \%$ of the total variance (i.e. the full meaning and variability within the data). Based on a series of output tables, the distinguishing statements for each group (positive, as well as neutral and negative statements) were qualitatively analyzed to explain the substance of the prevailing attitudes (Tables 2-5). Despite of the fact that based on our results, a reasonable proportion of the factors driving our results could be explained, it seems fair to indicate that still more than half of them remain unexplained. This leaves the door open for further reflections and ideas on causal relationships to be further tested in the future through methods other than $\mathrm{Q}$ that may help refine our current results.

\subsection{Characterization of the attitudinal groups identified}

Group 1 is perceived to be 'robust policy' supporters. Experts belonging to group 1 express critical and rather pessimistic attitudes towards existing practices of treeline governance. This group (through internal deliberation by the authors, illustratively labeled as pessimists) believes that there is a lack of trust in decision makers $(+5)$, that governance is implemented via top-down mechanisms $(+4)$ and that the
Table 2

Distinguishing statements for factor 1 .

\begin{tabular}{|c|c|c|c|}
\hline No. & Statement & RNK & Score \\
\hline 21 & There is a lack of trust in decision makers in treeline areas & 5 & $2.21 *$ \\
\hline 10 & $\begin{array}{l}\text { Governance in treeline areas is implemented through top- } \\
\text { down mechanisms }\end{array}$ & 4 & 1.74 \\
\hline 22 & $\begin{array}{l}\text { Decisions in treeline areas are usually made in such a way } \\
\text { that those in power take advantage }\end{array}$ & 4 & $1.65^{*}$ \\
\hline 27 & Markets are popular in treeline areas & 3 & $0.86^{*}$ \\
\hline 16 & Governance in treeline areas is flexible to changes & 1 & $0.12 *$ \\
\hline 18 & $\begin{array}{l}\text { Governance instruments enhance ecological sustainability } \\
\text { in treeline areas }\end{array}$ & 0 & 0.06 \\
\hline 13 & $\begin{array}{l}\text { Governance works as a balanced combination of bottom- } \\
\text { up and top-down approaches }\end{array}$ & 0 & -0.11 \\
\hline 15 & $\begin{array}{l}\text { Governance in treeline areas is a learning process from the } \\
\text { past }\end{array}$ & -3 & $-0.98^{*}$ \\
\hline 1 & $\begin{array}{l}\text { Relevant stakeholders have opportunities to participate in } \\
\text { land use planning }\end{array}$ & -5 & -1.67 \\
\hline
\end{tabular}

decisions are made in such a way that those in power take advantage $(+4)$. The perspectives of respondents belonging to this group are shown in Table 2. In the Tables 2 through $5, \mathrm{P}<0.05$; while the asterisks means that these statements are also significant at the $\mathrm{P}<0.01$ level.

Group 2 experts consider that stakeholders have opportunities to participate $(+4)$. In close alignment with attitudinal group 1 , they think that decision-making is carried out in such a way that those in power take advantage $(+2)$. However, they claim that the prosperity of local communities is the main policy objective $(+2)$ in treeline areas (Table 3 ). Also, (with a significance at $\mathrm{P}<0.01$ ), the attitudinal group 2 is neutral (or ambiguous) concerning the statement 6 that research answers major questions posed by policies.

This group perceived treeline decision-making as being implemented from the 'top-down for social objectives' $(+5)$; and these respondents seem to reflect a rather pragmatic point of view on problems related to governance, stakeholder involvement, and the use of knowledge in environmental decision-making. On this basis, we labeled the attitudinal group 2 as pragmatists.

Group 3 experts believe in the role of science in treeline governance $(+4)$ which involves a continuous two-way knowledge exchange between scientists and other policy actors $(+5)$. They suggest that research on treeline areas answers major questions posed by public decision makers $(+2)$. They also think that local land use planning meetings affect the decision-making process $(+3)$, and that mechanisms for decision-making are top-down $(+2)$. Group 3, whose attitudes and perspectives are illustrated in Table 4, was labeled as researchers. It seems to largely reflect the attitudes that scientific researchers could have, considering treeline governance as being 'non-green technocratic'.

Group 4 experts consider treeline governance as being 'green adaptive governance'. These experts support existing practices and consider them to be flexible to changes $(+5)$, and that governance instruments enhance the ecological sustainability $(+3)$. They believe that stakeholders participate in land use planning with the full confidence that their views are taken into account $(+1)$, and that governance involves a continuous two-way knowledge exchange between research scientists and other policy actors $(+1)$ (Table 5).

These experts reject statements that decisions in treeline areas are usually made in such a way that those in power take advantage, and that there exists a lack of trust in decision makers (especially public). They strongly disagree that decision-making is implemented through top-down mechanisms. However, they also reject the notion that existing governance instruments enable two-way knowledge transfer between stakeholders and regional and national administrations. Group 4, labeled as a community of practice, seems to reflect views that arise from within existing governance structures, and they give the impression that they are familiar with the managerial practices and 
Table 3

Distinguishing statements for factor 2 .

\begin{tabular}{|c|c|c|c|}
\hline No & Statement & RNK & Score \\
\hline 10 & Governance in treeline areas is implemented through top-down mechanisms & 5 & $2.40 *$ \\
\hline 1 & Relevant stakeholders have opportunities to participate in land use planning & 4 & $1.54^{*}$ \\
\hline 22 & Decisions in treeline areas are usually made in such a way that those in power take advantage & 2 & 0.89 \\
\hline 29 & Prosperity of local communities is the main policy objective in treeline areas & 2 & $0.72 *$ \\
\hline 6 & Research on treeline areas answers major questions posed by policies & 0 & 0.15 \\
\hline 18 & Governance instruments enhance ecological sustainability in treeline areas & -1 & 0.50 \\
\hline 14 & Governance instruments take into account special features of treeline areas & -1 & -0.62 \\
\hline 16 & Governance in treeline areas is flexible to changes & -2 & $-0.84 *$ \\
\hline 13 & Governance works as a balanced combination of bottom-up and top-down approaches & -4 & $-1.53^{*}$ \\
\hline 9 & Traditional (local) knowledge is equally weighted with scientific knowledge when decisions are made & -5 & -1.80 \\
\hline
\end{tabular}

decision-making problems on the ground.

\subsection{Comparative synthesis of the groups' attitudes}

Findings indicate commonalities in the attitudes of pessimists, pragmatists, and researchers (Figs. 2). All these groups consider that decision-making in treeline areas is implemented via top-down mechanisms $(+4,+5,+2)$. Pessimists and pragmatists also believe that decisions are made in such a way that those in power take advantage $(+4,+2)$. The main differences between opinions held by pessimists and pragmatists concern attitudes towards opportunities for stakeholders to participate in land use planning; attitudes to market based instruments, and to the flexibility of governance to changes. Also, in contrast to the attitudes of pessimists, researchers and representatives of our community of practice - for simplicity labeled as 'practitioners' $(-5,-3,0)$, pragmatists believe that stakeholders have opportunities to participate in land use planning $(+4)$. Pessimists and practitioners consider that governance is flexible to changes $(+1,+5)$. They believe that existing governance instruments may enhance ecological sustainability $(0,+3)$, while pragmatists and researchers hold opposite attitudes $(-1,-4)$.

Results indicate the following key areas of attitudinal disagreements among the four clustered groups identified: (i) trust in treeline public decision makers, (ii) stakeholders' opportunities to be adequately involved in governance, and (iii) ecological sustainability in treeline areas.

\subsection{Linking identified attitudes to background characteristics of respondents}

The modelling outputs demonstrate that 24 out of 30 respondents were uniquely and significantly associated with one of the 4 identified attitudinal groups (e.g. 8 respondents - with the first group). Three respondents were mixtures, and 3 respondents remain without a significant factor loading for any of the attitudinal groups. Therefore, the number of these groups was identified as not totally deterministic.

Results did not distinguish substantial differences in relation to socio-economic characteristics of respondents across the attitudinal
Table 5

Distinguishing statements for factor 4 .

\begin{tabular}{|c|c|c|c|}
\hline No & Statement & RNK & Score \\
\hline 16 & Governance in treeline areas is flexible to changes & 5 & $1.42 *$ \\
\hline 18 & $\begin{array}{l}\text { Governance instruments enhance ecological sustainability } \\
\text { in treeline areas }\end{array}$ & 3 & $1.09 *$ \\
\hline 3 & $\begin{array}{l}\text { Stakeholders are participating in land use planning with } \\
\text { full confidence that their views are taken into account }\end{array}$ & 1 & $0.65^{*}$ \\
\hline 12 & $\begin{array}{l}\text { Governance involves a continuous two-way knowledge } \\
\text { exchange between scientists and other policy actors }\end{array}$ & 1 & $0.49 *$ \\
\hline 1 & $\begin{array}{l}\text { Relevant stakeholders have opportunities to participate in } \\
\text { land use planning }\end{array}$ & 0 & $0.05^{*}$ \\
\hline 22 & $\begin{array}{l}\text { Decisions in treeline areas are usually made in such a way } \\
\text { that those in power take advantage }\end{array}$ & -1 & -0.05 \\
\hline 21 & There is a lack of trust in decision makers in treeline areas & -2 & $-1.14 *$ \\
\hline 11 & $\begin{array}{l}\text { Existing governance instruments enable two-way } \\
\text { knowledge transfer between local stakeholders and } \\
\text { regional and national administration }\end{array}$ & -4 & -1.42 \\
\hline 10 & $\begin{array}{l}\text { Governance in treeline areas is implemented through top- } \\
\text { down mechanisms }\end{array}$ & -4 & $-1.53^{*}$ \\
\hline
\end{tabular}

groups. However, pessimists and pragmatists primarily represented highly educated, married men who were involved in science. Researchers (despite this attitudinal group seemingly reflecting the attitudes of those involved in scientific research) was in fact comprised of respondents with quite a diverse background. However, in this particular survey, all of them were over 50 years old (this observation could be worth exploring further). The respondents belonging to the community of practice attitudinal group in fact did not come exclusively from the practice community. This attitudinal group was represented by male and female respondents of various professional backgrounds, education, and by those from under 30 to over 50 years old. Their socioeconomic characteristics were wider than of any other attitudinal group.

\section{Discussion}

To achieve multiple objectives in rural areas of high vulnerability, such as some treeline areas, a strong commitment and engagement by

Table 4

Distinguishing statements for factor 3.

\begin{tabular}{|c|c|c|c|}
\hline No & Statement & RNK & SCORE \\
\hline 12 & Governance involves a continuous two-way knowledge exchange between scientists and other policy actors & 5 & $1.91 *$ \\
\hline 7 & Scientific knowledge is taken into account when the decisions are made & 4 & $1.45^{*}$ \\
\hline 4 & Local land use planning meetings affect decision-making in treeline areas & 3 & $1.20 *$ \\
\hline 10 & Governance in treeline areas is implemented from the top-down & 2 & 1.14 \\
\hline 6 & Research on treeline areas answers major questions posed by policies & 2 & $0.92^{*}$ \\
\hline 22 & Decisions in treeline areas are usually made in such a way that those in power take advantage & -1 & -0.29 \\
\hline 1 & Relevant stakeholders have opportunities to participate in land use planning & -3 & -0.98 \\
\hline 17 & Numerous overlapping governance structures make the policy landscape in treeline areas messy & -3 & $-1.00^{*}$ \\
\hline 18 & Governance instruments enhance ecological sustainability in treeline areas & -4 & -1.24 \\
\hline 16 & Governance in treeline areas is flexible to changes & -5 & $-2.11 *$ \\
\hline
\end{tabular}




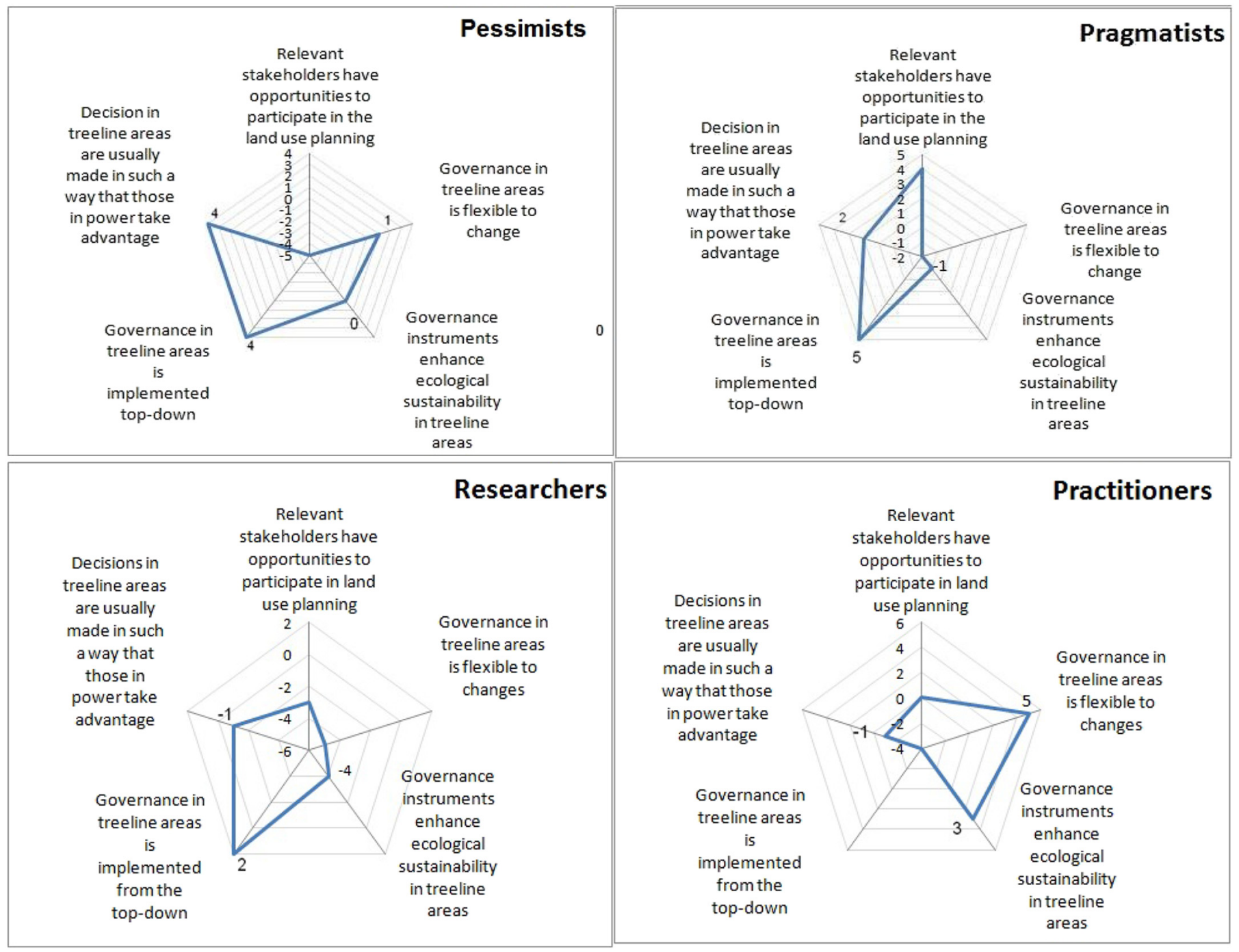

Fig. 2. Governance related attitudinal insights across the attitudinal groups.

the diverse stakeholders involved is required. These stakeholders (represented among our experts) include public and private decision makers, NGOs, businesses, public-private partnerships, rural development agencies, scientific communities, and civil society (Bizikova et al., 2012). Such a variety of stakeholders requires improved communication, collaboration and co-ordinated actions. However, stakeholder interests and their motives to manage and use ecosystems and their services in certain ways could be diverse and need to be well understood to be taken into account by public decision makers.

All attitudinal groups identified in our paper differ in their consideration of opportunities for relevant stakeholders to participate. Experts disagree on issues - i.e. that governance instruments enhance ecological sustainability; that governance in treeline areas is resilient and that decisions are made in such a way that those in power take advantage. However, a consensus is observed within the majority of attitudinal groups towards understanding that decisions in treeline areas are implemented through top-down mechanisms. A possible explanation for this inconsistency is that while participatory goals and agendas exist, they may not yet be efficiently implemented (Rauschmayer et al., 2009). This notion is in line with Nijnik and Oskam (2004) and Haila and Henle (2014) who show that the relationship between policy and its implementation can be among the key challenges in governing, also in treeline areas.

Common views across attitude-related communities may represent robust notions, if they are shared by heterogeneous groups of experts.
Some of our findings challenge, however, the existing skepticism in decision-making processes on land use changes, trust in public decision makers, and opportunities for relevant stakeholders to participate. All of these notions are challenged by those whom we categorized as practitioners, while trust and participation were identified by all throughout our study as key determinants of the quality of treeline area governance.

A potential inconsistency is also observed within the attitudinal group of pragmatists who consider governance as a top-down mechanism, while arguing that local stakeholders have opportunities to participate, although their knowledge is not taken into consideration for decision-making. This inconsistency can be explained by the existence of participatory fora which, however, do not allow genuine opportunities for participation, or by the fact that only certain stakeholders can actually participate in decision-making. Hence, these views likely reflect participation at a high level, thus being influenced by the top-down governance model currently perceived by experts.

A gap between existing policy objectives for local participation and their efficient implementation may be linked to the institutional inheritance and 'path dependency' in governance (Bizikova et al., 2012). To break path dependency stakeholder participation opportunities at local level need to be genuine (Arnstein, 1969). However, forest public and private decision makers may operate within dissimilar realities (Nie, 2003). They may act at different spatial and temporal scales and face gaps in realising different policies and practices in the decision- 
making processes (Krott, 2005; Hein et al., 2006). Therefore, identifying the range of contemporary discourses of treeline area governance is a necessary step towards improving the representation and inclusiveness of decision-making.

Also, our results show that the challenges are so complex and decision-making is still entrenched in top-down mechanisms that participatory planning cannot deliver according to its potential. This observation is in line with those of Muñoz-Rojas et al. (2015) and Duckett et al. (2016) which highlighted a range of "wicked" challenges in rural areas that the existing governance and planning models are unable to address. With respect to the challenges in treeline areas the results, on the one hand, showed problems with top-down decision-making related to the lack of opportunities for people on the ground to participate. On the other hand, we detected conflicting attitudes to the level of trust between local people and public decision makers across diverse scales affecting these opportunities.

This may be explained as follows. Firstly, it might be perceived that top-down coordination of decision-making is acceptable in some cases, and that the decisions of existing policy actors can be trusted. In other cases, however, top-down governance leads to a lack of trust in existing decision-making mechanisms (Sarkki, 2011). Secondly, top-down coordination does not always conflict with opportunities to participate, and as such the current governance model can be perceived as legitimate. This is somewhat surprising as the literature highlights that topdown decision-making is often deemed to lead to a crisis of legitimacy (Bäckstrand, 2003).

Given the ambiguity related to the environmental and social benefits of top-down decision-making more creative and effective multilevel governance is required (Newig and Fritsch, 2009). It should be underpinned by a long-term perspective allowing for on-the-ground, tailor-made solutions, useful for increasing support for forest policy and planning, whilst allowing for social innovations (SIMRA, 2016) and knowledge sharing. Presumably this will enable stakeholders to strengthen participation, build capacities, cooperation and trust, and develop competences so as to promote a balanced combination of adequate bottom-up and top-down decision-making approaches (Bizikova et al., 2012).

However, while ecological approaches places the emphasis on biodiversity conservation, which is particularly important in fragile treeline environments, there appeared to be conflicting attitudes to whether the existing governance model is environmentally beneficial. Given that a substantial proportion of treeline areas in Europe are legally designated for their natural or landscape values (EC, 2001) the EU environmental policy framework becomes particularly relevant, albeit the fact that the designated area governance model is considered to be rather top-down (Rauschmayer et al., 2009). The NATURA 2000 network, for example, has proven to have the potential to positively impact the environment (Paelinckx et al., 2008). However, achieving this objective would require enhancement of its site-level management (Louettea et al., 2011). The same argument can be applied to other EUdriven instruments for the greening of policy and decision-making in rural areas, such as the CAP Pillar II Agri-Environmental schemes, many of which strongly influence the sustainability and resilience of mountain areas across Europe.

This notion is complicated by our results for treeline areas which suggest that, according to some experts, top-down decision-making leads to environmentally beneficial management, while others think that top-down policy is clearly not fit for achieving environmental targets. This divergence in attitudes taken by different experts challenges two assumptions made by Newig and Fritsch (2009). Firstly, these authors show that proactive and socially consensual environmental policy objectives lead to positive environmental outcomes. This perception contrasts with the expert attitudes revealed in our research (the responses of the groups' 1-3 on statement 18). Secondly, Newig and Fritsch (2009) argue that polycentric governance models, including participatory arrangements, yields better environmental outcomes than monocentric top-down oriented governance models. Results from our evaluation of expert attitudes also challenge this notion, as we observed heterogeneous attitudes towards whether top-down mechanisms produce more environmentally beneficial effects than bottom-up, or not.

Importantly, the statements on governance and science-society interfaces were scored relatively close to average. This may be explained by the argument that many simultaneous instruments and scientific projects on the governance of rural areas exist (though these may not exist in treeline areas, on which COST Action ES1203 SENSFOR http:// www.sensfor-cost.eu/index.php/stsm constitutes quite a pioneering exception). Hence, respondents were possibly biased in their opinions by their knowledge of, or by direct participation in, these projects. Secondly, governance and science-society interfaces, in the majority of cases, work moderately well (Sarkki et al., 2015). However, knowledge that is co-constructed with public and private decision makers, and scientists is needed to develop measures that are coherent, effective, cost-efficient, widely locally acceptable, and consistent with other aspects of sustainable development-oriented strategies (Nijnik and Miller, 2014).

To conclude the discussion, we want to highlight that research results of Q-method studies are case and context specific. As our results are derived from an international expert opinion survey with the focus on European treeline areas, it may have a wide relevance. However we cannot argue that the method allows for extrapolation of results. We can't transfer our observations elsewhere and generalize the results. Therefore, we suggest complementing this research with studies with a similar design, as well as with an analysis of other complex institutional matters, such as policy and decision-making coordination, tenure rights and common pool resource problem solving. The use of scientific knowledge to inform environmental policies and multi-level governance would also require advances in the evaluation of ecosystem services as well as vertical and horizontal co-ordination of practical efforts (Jordan and Lenschow, 2010).

Finally, more effective governance would need improved understanding of key institutions and policy actors; identifying opportunities for social innovation; implementation of ecosystem based adaptation measures that consider dynamic and often unstable institutional structures; and providing guidance on consultation and participatory processes to ensure more effective stakeholder engagement in decisionmaking.

\section{Conclusions}

In this paper, we identified and characterized (for the case and contexts of this particular research) the heterogeneity of attitudes of selected stakeholders, mainly scientists and other experts, towards treeline area decision-making. The methodological approach applied intended to reach beyond the results obtained by using more traditional assessments of stakeholder attitudes, which were frequently aimed at identifying individual attitudes that would then be clustered based on certain explanatory variables, mainly social. It was done by incorporating in the design of our research a wider variety of elements influencing decision-making and governance models in treeline areas. These elements were reflected in the statements (e.g. concerning the level of participation in decision-making). Respondents scored the statements in line with their attitudes and perceptions. Based on the outcomes of scoring they assigned themselves into attitudinal groups. Differentiating the attitudinal types can help scientists improve stakeholder evaluation evidence base that could be used in subsequent analyses. Moreover, empirical evidence from this research indicates that certain background characteristics of respondents (e.g. education), were likely associated with attitudinal groups.

The approach and its application in Jaca, Spanish Pyrenees proved to be beneficial for both the researchers and experts, participating in discussions, and indirectly for local community, where the workshop was held. The design of participatory elements helped building trust 
and developing capabilities of all involved in the co-construction of knowledge. The method elaborated could potentially allow for mutual learning and capacity building, with the promotion of social innovation in other marginalised rural localities. It could also be recommended to policy actors and practitioners; while key results from this study could help provide decision makers (especially public) with some guidance for strategic planning and future development of treeline areas (e.g. by providing insights into opportunities and challenges of innovative forest governance).

The identified similarities in attitudes of our respondents (e.g. that key decisions are implemented through top-down mechanisms) could be helpful for reaching consensus among public and private local decision makers on certain contentious issues (e.g. that active stakeholder engagement and social innovation are a way forward). We also learned that the uncovered differences in views (including, on trust in public decision makers or concerning stakeholder opportunities to be involved in governance) can potentially lead to conflict situations among policy actors. Since our findings show that some key differences in experts' attitudes may be caused by value-conflicts, a participatory decisionmaking process may help in raising awareness of such differences and of the key problems that can arise in relation to conflict avoidance, management or resolution. The observed attitudinal differences could assist decision makers in addressing the opinion of each attitudinal group on a case-by-case basis, as well as in applying the most suitable solutions to problems where consensus can hardly be reached. However, the question as to whose values and preferences are most important remains challenging.

In line with Eckerberg and Sandstrom (2013) our findings advocate that participatory governance processes could be particularly useful for better targeting of the outcomes of technical and practice-oriented forest policy discussions. The achievement of targets would depend on co-ordination of practical efforts, wider stakeholder involvement in decision-making, and on building institutional capacities for closer integration of various policy initiatives into local plans and the promotion of socially innovative decision-making processes (Jordan and Lenschow, 2010). Consequently, progress in participatory-led decisionmaking may help in challenging the "wickedness" that is inherent to governance of marginalised rural areas of a multi-functional nature.

Although this is widely accepted knowledge, several additional points arise from our findings that turn our research results innovative in this context: i) this paper represents a first (and also to date) unique attempt to better understanding of attitudes and intentions of the scientific community and experts in the (potentially contentious) context of treeline areas, ii) even within a stakeholder community as closely bounded by their objectives, methods and tools as experts and scientific researchers, a great diversity in responses and interests towards a common objective (in this case, treeline area governance) can be disentangled, and iii) this paper demonstrates the potentialities shown by using Q-method to unveil subtle attitudinal approaches that would otherwise remain hidden.

To conclude, we believe that key findings from our research (i.e. concerning the heterogeneity of attitudes and/or improved participation in decision-making to promote social innovation) could be helpful in preventing and/or resolving potential conflicts, as well as the designing of policy and practice related measures, and better targeting of projects, plans and decisions, so that they may more effectively provide multiple benefits from treeline areas and their ecosystems.

\section{Acknowledgement}

This article is based upon work from Cost Action ES1203 Enhancing the Resilience Capacity of Sensitive Mountain Forest Ecosystem under Environmental Change (SENSFOR) and COST Action FP1207 Orchestring forest-related policy analysis in Europe (ORCHESTRA) supported by COST (European Cooperation in Science and Technology) No. 633054. We would also like to thank the Scottish Government who supported this research through their Rural Affairs and the Environment Strategic Research Programme and the European Commission for support provided to the project on Social Innovation in Marginalised Rural Areas (SIMRA) funded from the European Union's Horizon 2020 Reaserch and Innovation Programme, grant agreement No. 677622. We are grateful to respondents who contributed to the survey and to the anonymous reviewers for their helpful comments.

\section{References}

Addams, H., Proops, J., 2000. Social Discourse and Environmental Policy. An Application of Q Methodology. Edward Elgar, Cheltenham.

Adger, W.N., 2003. Social capital, collective action, and adaptation to climate change. Econ. Geogr. 79, 387-404.

Andonova, L., Mitchell, R., 2010. The rescaling of global environment politics. Annu. Rev. Environ. Resour. 35, 255-282.

Arnstein, S., 1969. A ladder of citizen participation. J. Am. Plan. Assoc. 35, 216-224.

Asheim, B.T., Isaksen, A., 2002. Regional innovation systems: the integration of local 'sticky' and global 'ubiquitous' knowledge. J. Technol. Transfer. 27 (1), 77-86.

Bäckstrand, K., 2003. Civic science for sustainability: reframing the role of experts, policy makers and citizens in environmental governance. Global Environ. Polit. 3, 24-41.

Barry, J., Proops, J., 1999. Seeking sustainability discourses with Q methodology. Ecol. Econ. 28, 337-345.

Berkes, F., 2009. Evolution of co-management: role of knowledge generation, bridging organizations and social learning. Environ. Manag. 90, 1692-1702.

Bizikova, L., Nijnik, M., Kluvanková-Oravská, T., 2012. Sustaining multi-functional forestry through the developing of social capital and promoting participation: a case of multiethnic mountain communities. Small Scale For. 11 (3), 301-319.

Bock, B., 2015. Rural marginalisation and the role of social innovation; a turn towards Nexogenous development and rural reconnection. Sociol. Rural. 56 (4).

Brang, P., Schönenberger, W., Frehner, M., Schwitter, R., Thormann, J.-J., Wasser, B., 2006. Management of protection forests in the European Alps: an overview. Forest Snow and Landscape Research 80, 23-44.

Brown, S.R., 1999. A primer on Q-method. Operant Subjectivity J. 16 (3/4), 91-138.

Brown, M., 2004. Illuminating Patterns of Perception: An Overview of Q Methodology. Carnegie Mellon University, Pittsburgh, PA 15213.

Bürgi, M., Hersperger, A.N., Schneeberger, N., 2004. Driving forces of landscape change current and new directions. Landsc. Ecol. 19, 857-868.

Cajaiba-Santana, G., 2014. Social innovation: moving the field forward. A conceptual framework. Technol. Forecast. Soc. Chang. 82, 42-51.

Camagni, R., 1995. The concept of innovative milieu and its applicability for public policies in European lagging regions. Pap. Reg. Sci. 74 (4), 317-340.

Coleman, J., 1988. Social capital in the creation of human capital. Am. J. Sociol. 94 (1), s95-120.

Cuppen, E., 2009. Putting Perspectives into Participation-Constructive Conflict Method for Problem Structuring in Stakeholder Dialogues. Uitgeverij BOXPress, Oisterwijk.

Davies, B., Hodge, I., 2012. Shifting environmental perspectives in agriculture: repeated $\mathrm{Q}$ analysis and the stability of preference structures. Ecol. Econ. 83, 51-57.

Davies, B., Sherlock, K., Rauschmayer, F., 2005. 'Recruitment', 'composition' and 'mandate' issues in deliberative processes: should we focus on arguments rather than individuals? Environ. Plann. C 23, 599-615.

Duckett, D., Feliciano, D., Martín-Ortega, J., Muñoz-Rojas, J., 2016. Tackling wicked environmental problems: the discourse and its influence on praxis in Scotland. Landsc. Urban Plan. 154, 44-56.

Eckerberg, K., Sandstrom, C., 2013. Preface to forest conflicts: a growing research field Forest Policy Econ. 33, 3-7.

Ericsson, K.A., Charness, N., Feltovich, P., Hoffman, R.R., 2006. The Cambridge Handbook of Expertise and Expert Performance. Cambridge University Press, Cambridge, UK.

European Commission (EC), 2001. European Governance: a White Paper. In: COM (2001) 428 final, Brussels.

European Commission (EC), 2010. 10 messages for 2010 Forest Ecosystems. European Environmental Agency. http://www.eea.europa.eu/publications/ (accessed 10.08.15).

European Commission (EC), 2016. Social innovation. http://www. socialinnovationeurope.eu/ (web archive link, 20 March 2017)http://ec.europa.eu/ programmes/horizon2020/en/h2020-section/societal-challenges (web archive link, 20 March 2017)http://siresearch.eu/social-innovation/research-projects (accessed 20.03.17).

European Environment Agency (EEA), 2010. Europe's Ecological Backbone: recognising the true value of our mountains. In: EEA Report 6/2010. Copenhagen, EEA.

van Exel, J., De Graaf, G., 2005. Q Methodology: A Sneak Preview. Rotterdam.

Fukuyama, F., 1995. Trust: the social virtues and the creation of prosperity. Bus. Econ. 457

Funtowicz, S.O., Ravetz, J., 1993. Science for the postnormal age. Futures 25, 739-755.

Gellrich, M., Baur, P., Koch, B., Zimmermann, N.E., 2007. Agricultural land abandonment and natural forest re-growth in the Swiss mountains: a spatially explicit economic analysis. Agric. Ecosyst. Environ. 118, 93-108.

González-Puente, M., Campos, M., McCall, M., Muñoz-Rojas, J., 2014. Places beyond maps; integrating spatial map analysis and perception studies to unravel landscape change in a Mediterranean mountain area (NE Spain). Appl. Geogr. 52, 182-190.

Gret-Regamey, A., Brunner, S.H., Altwegg, J., Christen, M., Bebi, P., 2013. Integrating expert knowledge into mapping ecosystem services trade-offs for sustainable forest 
management. Ecol. Soc. 18 (3), 34. http://dx.doi.org/10.5751/ES-05800-180334. (accessed 10.08.15).

Haas, P., 1992. Introduction: epistemic communities and international policy coordination. Int. Organ. 46 (1), 1-35.

Haila, Y., Henle, K., 2014. Uncertainty in biodiversity science, policy and management: a conceptual overview. Nat. Conserv. 8, 27-43.

Heikkinen, H.I., Sarkki, S., Jokinen, M., Fornander, D., 2010. Global area conservation ideals versus the local realities of reindeer herding in Northernmost Finland. Int. J. Bus. Global. 4 (2), 110-130.

Heikkinen, H. I., Sarkki, S., Nuttall, M., 2012. Users or producers of ecosystem services? A scenario exercise for integrating conservation and reindeer herding in northeast Finland 2, 11.

Hein, L., Koppen, K.V., de Groot, R.S., Ierland, E.S., 2006. Spatial scales, stakeholders and the valuation of ecosystem services. Ecol. Econ. 57, 209-228.

Hermans, F., Kok, K., Beers, P.J., Veldkamp, T., 2012. Assessing sustainability perspectives in rural innovation projects using Q-methodology. Sociol. Rural. 52 (1), 70-91.

Hodge, I., 2013. The governance of rural landscapes: property, complexity and policy. Chapter 5. In: van der Heide, M., Heijman, W. (Eds.), The Economic Value of Landscape. Routledge, London, pp. 88-100.

Huber, R., Bugmann, H., Buttler, A., Rigling, A., 2013. Sustainable landuse practices in European mountain regions under global change: an integrated research approach. Ecol. Soc. 18 (3), 37. http://dx.doi.org/10.5751/ES-05375-180337. (accessed 10. 08.15).

Jessop, B., Sum, N.-L., 2006. Beyond the Regulation Approach Putting Capitalist Economies in their Place. Edward Elgar, Cheltenham.

Jordan, A., Lenschow, A., 2010. Environmental policy integration: a state of the art review. Environ. Pol. Govern. 20, 147-158.

Kaljonen, M., Primmer, E., de Blust, G., Nijnik, M., Kulvik, M., 2008. Multi-functionality and biodiversity conservation - institutional challenges. In: Chmielewski, T.J. (Ed.), Nature Conservation Management: From Idea to Practical Issues. ALTER-NET, PWZN Print 6. Lublin-Lodz-Helsinki-Aarhus, pp. 113-132.

Krott, M., 2005. Forest Policy Analysis. Kluwer Academic Publisher, Dordrecht.

Lasanta, T., Vicente-Serrano, S.M., Cuadrat, J.M., 2005. Mountain Mediterranean landscape evolution caused by the abandonment of traditional primary activities: a study of the Spanish Central Pyrenees. Appl. Geogr. 25, 47-65.

Lasswell, H.D., 1971. The Evolution of the Policy Sciences. In: Lasswell, H.D. (Ed.), A Preview of Policy Sciences. American Elsevier Publishing, New York, pp. 1-13.

Lehtonen, M., 2004. The environmental-social interface of sustainable development: capabilities, social capital, institutions. Ecol. Econ. 49 (2), 199-214.

Louettea, G., Adriaensa, D., Adriaensa, P., Anselina, A., Devosa, K., Sannenb, K., van Landuyta, W., Paelinckxa, D., Hoffmanna, M., 2011. Bridging the gap between the Natura 2000 regional conservation status and local conservation objectives. J. Nat. Conserv. 19 (4), 224-235.

McKeown, B., Thomas, B., 2013. Q Methodology. Sage Publications.

Miller, D.R., Vogt, N., Nijnik, M., Brondizio, E., Fiorini, S., 2009. Integrating analytical and participatory techniques for planning the sustainable use of land resources and landscapes. In: Geerteman, S., Stillwell, J. (Eds.), Plan Support Systems: Best Practises and New Methods. Springer Publs.

Muñoz-Rojas, J., Nijnik, M., Puente, M.G., Garcia, F.C., 2015. Synergies and conflicts in the use of policy and planning instruments for implementing forest and woodland corridors and networks in Scotland. Forest Policy Econ. 57, 47-64.

Neumeier, S., 2016. Social innovation in rural development: identifying the key factors of success. Geogr. J. http://dx.doi.org/10.1111/geoj.12180.

Newig, J., Fritsch, O., 2009. Environmental governance: participatory, multi-level-and effective? Environ. Pol. Govern. 19, 197-214.

Nie, M., 2003. Drivers of natural resource-based political conflict. Policy. Sci. 36, 307-341.

Nijnik, M., Miller, D., 2014. Targeting sustainable provision of ecosystem services with special focus on carbon sequestration. In: Matyssek, R., Clarke, N., Cudlin, P., Mikkelsen, T., Tuovinen, J.-P., Wiesser, G., Paoletti, E. (Eds.), Climate Change, Air Pollution and Global Challenges: Understanding and Solutions. Elsevier.
Nijnik, M., Oskam, A., 2004. Governance in Ukrainian forestry: trends, impacts and remedies. Int. J. Agric. Resour. Govern. Ecol. 3 (133), 116.

Nijnik, M., Nijnik, A., Lundin, L., Staszewski, T., Postolache, C., 2010. Stakeholder attitudes to multi-functional forests in Europe. Forests, Trees and Livelihoods 19 (4), 341-358.

Nijnik, M., Nijnik, A., Bergsma, E., Matthews, R., 2014. Heterogeneity of experts' opinion regarding opportunities and challenges of tackling deforestation in the tropics. Mitig. Adapt. Strateg. Glob. Chang. 19 (6), 621-640.

Nijnik, M., Nijnik, A., Brown, I., 2016. Exploring the linkages between multi-functional forestry goals and the legacy of spruce plantations in Scotland. Can. J. For. Res. http://dx.doi.org/10.1139/cjfr-2015-0399. (accessed 12.08.16).

Ostrom, E., 2011. Background on the institutional analysis and development framework. Pol. Stud. J. 39, 7-27.

Paelinckx, D., van Landuyt, W., De Bruyn, L., 2008. Conservation status of the Natura 2000 habitats and species. In: INBO.R.2008.15, Brussels.

Previte, J., Pini, B., Haslam-McKenzie, F., 2007. Q Methodology and rural research. Sociol. Rural. 47, 135-147.

Putnam, R., 2000. Bowling Alone: The Collapse and Revival of American Community. Simon \& Schuster, New York.

Rauschmayer, F., van den Hove, S., Koetz, T., 2009. Participation in EU biodiversity governance: how far beyond rhetoric? Environ. Plann. C Govern. Pol. 27 (1), 42-58.

Robbins, P., 2005. Q methodology. In: Kempf-Leonard, K. (Ed.), Encyclopaedia of Social Measurement. Elsevier, London, pp. 209-216.

Sandström, C., 2009. Institutional dimensions of co-management: participation, power and process. Soc. Nat. Resour. 22 (3), 230-244.

Sarkki, S., 2011. The Site Strikes Back: Multi-level forest governance and participation in northern Finland. PhD thesis. Thule Institute and Discipline of Anthropology, University of Oulu, Finland. Acta Universitatis Ouluensis B, pp. 102.

Sarkki, S., Heikkinen, H., 2010. Social movements' pressure strategies during forest disputes in Finland. J. Nat. Resour. Pol. Res. 2 (3), 281-296.

Sarkki, S., Heikkinen, H.I., Karjalainen, T.P., 2013. Sensitivity in transdisciplinary projects: case of reindeer management in Northern Finland. Land Use Policy 34, 183-192.

Sarkki, S., Niemelä, J., Tinch, R., van den Hove, S., Watt, A., Young, J., 2014. Balancing credibility, relevance and legitimacy: a critical assessment of trade-offs in sciencepolicy interfaces. Sci. Public Policy 41 (2), 194-206.

Sarkki, S., Ficko, A., Grunewald, K., Nijnik, M., 2015. Benefits from and threats to European treeline ecosystem services: an exploratory study of stakeholders and governance. Reg. Environ. Chang. 16 (7), 2019-2032.

Schmolck, P., 2012. PQMethod version. pp. 2.33. http://schmolk.userweb.mwn.de/ qmethod/ (accessed 10.08.15).

SENSFOR, 2013. COST Action ES2013, Enhancing the Resilience Capacity of Sensitive Mountain Forest Ecosystem under Environmental Change, Brussels.

SIMRA, 2016. Social Innovation in Marginalised Rural Areas. Innovative, Sustainable and Inclusive Bioeconomy, Topic ISIB-03-2015. Unlocking the growth potential of rural areas through enhanced governance and social innovation. In: European Union Framework Programme Horizon 2020, Brussels.

Stephenson, W., 1963. Independency and operationism in Q-sorting. Psychol. Rec. 13 269-272.

Stevenson, H., 2015. Contemporary discourses of green political economy: a Q method analysis. J. Environ. Policy Plan. http://dx.doi.org/10.1080/1523908 X.2015. 1118681. accessed. 10.08.15.

Stirling, A., 2006. Precaution, foresight and sustainability: reflection and reflexivity in governance of science and technology. In: Vos, J., Bauktnecht, D., Kemp, R. (Eds.), Reflexive Governance for Sustainable Development. Edward Edgar, Cheltenham, pp. 225-272.

Watts, S., Stenner, P., 2012. Doing Q Methodological Research: Theory, Method and Interpretation. Sage, London.

Wilson, D.C., 2009. The Paradoxes of Transparency Science and the Ecosystem Approach to Fisheries Management in Europe. Amsterdam. University Press, Amsterdam. 